\title{
5. Inside and Outside: Contrasting Perspectives on the Dynamics of Kinship and Marriage in Contemporary South Asian Transnational Networks ${ }^{(1)}$
}

\author{
Roger Ballard University of Manchester
}

\section{Introduction}

In much of the Euro-American world, the possibility that family life might be reaching a point of collapse has emerged as a regular focus of increasingly anxious public debate. It is easy to see why. Besides steadily eroding the range and intensity of networks of extra-familial kinship reciprocity, such that such relationships are but a shadow of their former selves, the ever-more active pursuit of personal freedom has now begun to have a similar impact on the integrity of the nuclear family itself. The results are plain to see. In the face of the apparently inexorable rise in the frequency of divorce, even the institution of marriage is falling steadily out of favour. But in contrast to the way in which these developments have precipitated urgent public discussions about the prospect of reinforcing shrinking levels of familial solidarity, this chapter explores a set of issues lying right at the other end of the spectrum: those in which a perceived degree of over-commitment to familial solidarity is alleged to be precipitating such serious challenges to human and personal rights that urgent legislative efforts are now required to contain their pathogenic consequences.

Such developments might seem bewildering, but for the context within which they have erupted. The underlying contradictions which have driven these arguments forward have little, if anything to do with kinship per se, or even with human rights, though this provides the legitimising framework within which the debate is set. Instead they are better understood as the outcome of contradictions generated by the rapid growth in the scale of the nonEuropean presence which processes of mass-migration and globalisation have precipitated during the past half century.

Why, though, should family and kinship have become such a serious battleground in this context? On the face of it such matters would appear to be peripheral, since public concern in this sphere is primarily directed at the competitive threat which the inflow of immigrants is perceived as offering to the material interests of the indigenous majority. Hence popular concern was initially articulated in terms of fears about the extent to which newcomers would steal jobs, lower wages, precipitate a shortage of housing and place an unreasonable burden on scarce public services. By contrast, the current debate with respect to non-European settlers' preferred patterns of kinship solidarity has a different focus. In the light of wider concerns about the declining resilience of family ties amongst the indigenous population, one might expect that in this respect, at least, the consequences of the settlers'

(1) This chapter is a product of forty years of close observation of processes of inter-personal interaction in South Asian families. This began when I conducted fieldwork in Himachal Pradesh for my doctoral thesis at Delhi University, and was powerfully reinforced when I was subsequently appointed to one of the earliest research posts directed at exploring developments within the South Asian community in Britain. Hence the principal source on which I have drawn in constructing the arguments and analyses set out in this chapter are my own personal observations of patterns of behaviour within Hindu, Sikh and Muslim families based in the Pennine region of northern England, and from extended periods of ethnographic fieldwork in Punjab and Azad Kashmir. In recent years I have been able to supplement these ethnographic observations with the analysis of statements on which I have been instructed to reflect in the course of preparing more than four hundred expert reports for use in proceedings in the Civil, Criminal, Family and Immigration courts in which South Asian settlers and their offspring have been involved. 
commitment to kinship solidarity might be regarded as welcome. That expectation may have had some substance when they first arrive, but now popular opinion towards them is no more positive in this sphere than in any other.

The reasons for this deserve careful examination. Critiques of the settlers' practices largely ignore the manifold benefits which the maintenance of extended networks of kinship reciprocity routinely precipitate. Instead they are primarily concerned with the relative weight that should be given to the right of every individual to determine his or her own futures on a wholly autonomous basis, as opposed to the freedom-limiting patterns of duties and obligations with which participants in networks of mutual reciprocity amongst kinsfolk are required to subordinate themselves. Debates about such matters swiftly precipitate much argument about the legitimacy of specific forms of practice - most especially in terms of marriage, family and household formation - to which the use of such corporately-oriented values give rise. In exploring the logic of the resultant arguments this chapter will swing back and forth between policy as opposed to practice, between ideological norms and their behavioural implementation, and above all between the often radically different insiders' and outsiders' perspectives on, and interests in, what is happening.

The social and cultural landscape of most of Europe's major towns and cities has been transformed during the course of past half century. Thanks to the arrival of substantial numbers of non-European settlers, each has been rendered markedly more plural in character. As a result cross-cultural communication has become the locus of increasingly salient sociopolitical contradictions. Where those on either side of an ethnic disjunction are unfamiliar with each other's conceptual vocabulary, those making efforts to communicate across the disjunction can all too easily find themselves talking past each other, rather than to each other. In such contexts of mutual miscommunication, the linked concepts of 'inside' and 'outside' are of crucial analytical significance. But in adopting such a terminology it is vital to remember that the contending perspectives are rarely, if ever, of equal socio-political weight. One of the most salient features of our current context is that members of the dominant majority (who we can more explicitly identify as the indigenes, the whites, the hosts, the natives, perhaps most comfortably of all as the Europeans) routinely conceive of themselves as legitimate insiders vis-à-vis members of more recently arrived immigrant, alien, nonEuropean minorities who have settled in their midst. Having thus defined themselves as insiders in contra-distinction to such 'immigrant' outsiders, they routinely assume that their own conventions and expectations about the ways in which one should organise kinship and marriage are normal, natural and proper. And having established their own behavioural their taken-for granted, and hence necessarily parochial, conceptual vision as the yardstick of normality, if newcomers deploy conventions which differ significantly from their own, their behaviours are marked out as alien, artificial, improper, and at worst as illegitimate, by comparison with those enshrined within the established socio-cultural order (Ballard 2006).

Of course, within the safety of the settlers' own self-constructed worlds, this evaluation is frequently stood on its head. From the 'outsiders' insider perspective, it is the 'alien' ways which they have brought with them from their distant homelands which are deemed to be normal and natural, whilst those routinely deployed by the indigenes amongst whom they have settled will be perceived as alien, artificial and unnatural. Concepts of inside and outside are by definition mutually interchangeable.

Issues of relative power further condition these perceptions. Those fortunate enough to occupy a position of hegemonic advantage tend to be blissfully unaware of the parochial 
character of the conceptual schema within which they operate. Hence they routinely view their own perspectives as so intrinsically superior to those of all others as to be of universal applicability. Those entrenched within such a condition of ethnocentric myopia have access to ready means of turning any complaints which 'outsiders' might make about the difficulties they have encountered back on the complainants themselves. From their position of unacknowledged hegemony, it seems self-evident that if only settlers had made greater efforts to assimilate to established European norms, rather than clustering mindlessly together, they would have won a much higher level of acceptance. As a result the newcomers bizarre and baffling commitment to the maintenance of alterity has become a focus of ever-more vigorous criticism as time has passed; and as 'insider' demands that the 'outsiders' should assimilate have become steadily more intense, popular representations of the outsiders' preferred lifestyles have become steadily more hostile. No longer are they merely viewed as exotically oriental, but are represented as being inherently oppressive, immoral, barbaric and terroristic, the very antithesis of the civilised European traditions which comfortably established insiders insist they have every right to sustain and defend (Ballard 2007).

In seeking to explore the dynamics of an increasingly fervent debate, the central focus of this chapter is the role which issues of kinship and marriage have come to play as those standing on both sides of the disjunction have sought both to advance their interests, and to legitimise their strategic efforts to do so, in the midst of sharpening levels of ethnic polarisation.

\section{Migration and its Consequences: A View from Above}

Since the collapse of the Soviet Union, and subsequently of the twin towers, Euro-America has discovered a new threat to its integrity: Islamic fundamentalism has slipped neatly into the space once occupied by the Red Menace. But whilst the American perspective has largely settled on the view that the principle threat to its integrity is external, such that its freedoms are best preserved by waging a 'war on terror' beyond its borders, the prism through which Europeans have perceived these self-same issues is of a different order. It is easy to see why. In the USA, the vast majority of migrant workers who arrived during the course of the past half century were overwhelmingly Hispanic in origin; by contrast their counterparts in Western Europe were overwhelmingly Muslim. Hence whilst the principal American response to the events of 9/11 was to engage in external military adventures (Afghanistan, Iraq), the European response to the attack on the twin towers and subsequent outrages in Madrid and London was quite different. The outrages served to reinforce a trope that had been gathering strength for several decades, namely that the most pressing threat to the integrity of

Europe's many nations arose from the presence of the Muslim minorities whose members had stealthily insinuated themselves within their borders. Against that background this chapter it is not concerned with Europe's anti-terrorist initiatives, but rather with a similarly grounded debate which runs in parallel to those developments, one which suggests that the cultural commitments of the new minorities, and especially the ways in which they have begun to utilise their distinctive conventions of kinship, marriage and family organisation to their own advantage, offer just as serious a challenge to the integrity of western Europe's established socio-cultural order.

Whilst paranoid concerns about the rising influence of religious fundamentalism are very largely a post-9/11 phenomenon, debates about the prospective significance of non- 
European settlers' commitment to distinctive kinship conventions have a much longer history. As is invariably the case in the initial stages of migration, the early pioneers of the nonEuropean inflow were young men in their twenties and early thirties who were content, at least at the outset, to leave their families back home, and then to take lengthy furloughs in their company to enjoy the fruits of hard earned savings. However the personal costs associated with such a strategy of trans-continental commuting were substantial, so it was not long before an ever increasing number of non-European sojourners took the next step and began to call their wives and children to join them, and hence transformed themselves into more permanently rooted settlers (Ballard 2003, 1994).

As their settlements grew steadily in scale, it soon became apparent that the social and cultural conventions which the newcomers' preferred to deploy in organising their domestic and personal lives were a matter of substantial socio-political consequence. In sharp contradiction to indigenous hopes and expectations the settlers showed little sign of assimilating into the mass of the surrounding population: instead they rapidly set about constructing ethnic colonies, within which all the most significant social, cultural and religious institutions of their homelands began to reappear. Indigenous reactions varied markedly by social class, especially at the outset. Since the vast majority of migrants settled in impoverished inner-city areas, their presence, and the deep-seated alterity of their domestic lifestyles, was largely unnoticed by anyone other than their immediate working-class neighbours. Hence no matter how alarmed and challenged their neighbours may have been by their alterity, the vast majority of more affluent outsiders took the view that the white working class response was simply a product of ignorant racism. Hence they were able to reassure themselves that behavioural oddities of which the settlers' inner city neighbours so insistently complained would soon be swept away by the inevitable process of assimilation.

Those days have long since passed. Whilst the settlers and their locally-born offspring are still largely concentrated in the same localities in which they first put down roots, such that there is still a substantial social distance between them and more prosperous members of the indigenous majority, public awareness of the existence of such ethnic colonies and their pluralising impact on the local social order is much more widespread. It is equally apparent that these developments are in no sense temporary. It is not just the older generation of settlers who remain committed to the maintenance of their own distinctive lifestyles; so, too, do their locally born offspring. To be sure the second generation are far more familiar with the ways of the indigenous majority than their parents, such that they have acquired the navigational skills which enable them to order their presentation of themselves in terms of majority conventions and expectations as and when they choose. Nevertheless most still quietly signal their alterity even in the most public arenas, whilst maintaining those commitments far more actively in personal, domestic and leisure contexts (Ballard 1994, Shaw 2000).

As the minorities' ethnic colonies have continued to burgeon, so majoritarian outsiders have come to view their vitality with ever-greater levels of concern. Feelings of hostility and alarm with respect to their presence is no longer confined to the white working class population of inner city where most, although by no means all, of these colonies remain spatially grounded. Certainly, those feelings remain most intense amongst those whose interests have been most directly challenged by the presence of the new minorities, but the range of those affected by such concerns has expanded way beyond the inner cities, to encompass ever wider swathes of the population at large. Suggestions that the heightened levels of plurality precipitated by the minority presence add a welcome touch of spice to the 
humdrum patterns of established practice have by now lost virtually all the traction they once had. Instead these developments are now routinely viewed as an unwelcome and indigestible threat to the integrity of the established socio-cultural order (Ballard 2007, Ali, Kalra and Sayyid 2006).

\section{Alterity in the Headlines}

Whilst it was to be expected that such developments would attract the attention of the popular press, the extensive, but unremittingly sensationalist, coverage they have received over the years have done little more than mirror, and hence exacerbate, the underlying contradictions. Stories revealing 'the shocking truth' about one aspect or another of 'immigrants' (it has long been unnecessary to specify their colour) and their lifestyles have been a regular source of dramatic headlines for the best part of half a century. At the outset most such accounts focussed on the squalid conditions in which the settlers lived, together with their willingness to work for next to nothing, so enabling unscrupulous employers to undermine all the achievements of the trades union movement. Following the introduction of immigration controls -themselves introduced to assuage such fears - attention began to switch to the ever more inventive strategies which would-be settlers began to deploy in their efforts to evade them. Whilst reports on these themes continue to appear, they have since been supplemented by stories highlighting the 'excessive' rates of fertility displayed by migrant mothers, as well as the marked proclivity of settlers to arrange the marriages of their offspring with spouses from back home, so comprehensively undermining the authorities' efforts to bring 'primary migration' to an end.

This has led to the most recent chapter of much-headlined revelations: lurid accounts of Forced Marriages and Honour Killings, of ways in which international gangs of 'peoplesmugglers' have forced their victims into servitude as prostitutes and cockle pickers, and of mysterious underground Hawala operations by means of which huge sums of 'dirty' money have been filtered through transnational networks to unknown destinations overseas. In highlighting these developments, I would in no way wish to suggest that incidents and processes to which these stories refer are fictitious. To be sure they are invariably sensationalised, but nevertheless they are largely grounded in reality. Rather my concern here is with the perspective from which they have been prepared. Driven by the priorities of their readers no less than their editors, few journalists have sought to step across the ethnic disjunction on whose significance they have sought to comment. As a result their stories, together with the public discussion which such accounts have generated, have remained relentlessly externalist and problem-focussed. Such perspectives have rarely been challenged. When allegedly authentic accounts of the experiences of those standing on the far side of the fence do emerge as a focus of public discussion, they are all too often framed in such a way as to confirm, rather than to contest, the normative expectations of the hegemonic majority. The attention paid to the experiences of Ayaan Hirsi Ali provides a spectacular example of just tendency.

What then, has been the shape of the normative expectations precipitated by these processes? So far as most members of Europe's indigenous majority are concerned, the intensifying socio-political contradictions which have been precipitated by the settlers' arrival are largely the fault of the settlers themselves. The emergent consensus has coalesced around the view that if only the settlers had made more urgent efforts to adjust, and better still to 
abandon, their ancestral heritage, they would have received a far warmer welcome. If they have found themselves confronted by escalating displays of hostility as a result of their dogged pursuit of perverse and unwelcome strategies of non-assimilation, the settlers and still more their offspring have only themselves to blame. Had they been prepared to behave more cooperatively and hence less transgressively, thereby displaying a greater degree of respect for the underlying principles of European civilisation, the current impasse would not have arisen.

Not surprisingly, the view from the other side of the fence stands most of these arguments on their heads. From their perspective the principal cause of their shift of residence was economic. Without the input of their labour, and their willingness to perform all manner of dirty, heavy and unpleasant tasks from which members of the indigenous population had withdrawn, Europe's economy would be in dire straights. But their alternative vision of their position in the global economy goes much further than that. Even though the role which they were initially required to perform was to act as the low-paid collectors of their hegemons' garbage, they had no intention of staying there. Their central objective in moving into the transnational labour market was not to reproduce their role as helots, but to transcend it, and to build a better material future for themselves and their families. By invading the territory of their former colonial masters, few could fail to be aware that in doing so they were engaging in a transgressive initiative of global, no less than parochial, significance. Moreover as former colonial subjects, they were well aware their former masters had little interest in, or respect for, the cultural and religious practices of those over whom they had imposed their rule, and no interest whatsoever in adopting those practices as a significant component of the own colonial lifestyles.

Hence, despite the fact that post-war migrant entrepreneurs were transgressors 'from below' rather than 'from above', the circumstances in which they found themselves were far from unfamiliar. No matter how disappointed they may have been to discover that the European evaluations of their status and capabilities was no more positive in the metropolis as it was in the colonies, their experience of being so treated was hardly novel; moreover, however much the Europeans might urge them to adopt indigenous cultural conventions and assimilate, they were well aware that European settlers had in no way behaved in such a manner when they themselves engaged in transnational migration from above.

\section{The Emergence of Ethnic Colonies}

This is not to suggest that the settlers remained untouched by the context in which they found themselves. Interaction with the hegemonic order which surrounded them was unavoidable, not least in the most essential task which faced them when they arrived at their destination, making a living. And as they rapidly discovered, the natives were rarely, if ever, prepared to go out of their way to help them find their feet. Hence it swiftly became self-evident that by far the best means of finding a roof beneath which to shelter, a job by means of which to support themselves, was through the good offices of those in the same boat, and especially those with whom they shared some degree of linguistic and cultural commonality. Thus the processes of ethnic crystallisation - driven by the need to build a resilient, mutually supportive and emotionally comfortable 'inside' world, the better to cope with, and to survive in the alien universe into which they had inserted themselves - began almost from the moment when pioneer migrants first stepped ashore. And since the networks of mutual 
reciprocity so generated provided such effective sources of material and psychological support, successive waves of settlers tapped into them at the earliest possible opportunity.

From this perspective ethnic aggregations were in no sense the outcome of a mindless commitment to traditionalism. Rather they were precipitated by settlers' creative utilisation of the resources embedded in their ancestral cultural traditions as they set about devising adaptive strategies the better to cope with the multitude of practical challenges with which they found themselves confronted. These initiatives in no sense represented a withdrawal from the wider social order in which they found themselves. On the contrary, they are better understood as a vital component of the way in which they engaged with the world around them, and which in no way excluded parallel efforts to acquire the social, linguistic and cultural skills which would also enable them to handle face-to-face interactions with members of the indigenous majority as and when required. They were well aware that if they were ever to move away from the positions at the bottom of socio-economic order to which they had been so humiliatingly ascribe, it was essential to acquire such skills.

But by the same token it was equally clear that mere conformity was an insufficient basis for everyday survival, let alone for achieving their more distant dreams of upward mobility. The natives were manifestly far too hostile, and their strategies of exclusion far too effective for them to achieve those goals without extensive and determined 'insider' activity on their account. Hence whilst by no means averse in acquiring the linguistic and cultural required to participate in arenas where conformity with indigenous conventions was a necessity, most settlers put much more energy into the construction of their own alternative networks of mutual support. In doing so the reciprocities that could readily be generated on the basis of ideologies of kinship proved to be particularly helpful, not least because of their inherent flexibility. At least at the outset pioneers whose prior connections ranged from tenuous to non-existent could readily utilise idioms quasi-kinship, so enabling them to construct binding relationships of reciprocity between themselves by acting as if they were brothers. However it was not long before chain-migration hastened the emergence of ever more coherent ethnic colonies ground in reciprocities of real rather than fictive kinship, precipitating the outcomes to which headline-writers subsequently reacted with such alarm.

\section{Kinship and the Construction and Maintenance of Transnational Networks}

Analysts of migration have paid remarkably little attention to matters of kinship. Whilst textbook accounts routinely point to the way in which transnational migrants have been 'pulled' by the insatiable demand for cheap and willing labour in the world's most prosperous economies, and 'pushed' by sharpening levels of relative poverty experienced by the inhabitants of much of Asia, Africa and Latin America, much less attention has yet been paid to the human processes which have which have sustained the internal dynamics of each of these many separate population-flows. As a result there is still only a dawning recognition that the success with which they are continuing to sweep across ever more heavily defended borders is to a large extent a consequence of a further factor: the extent to which these processes are kinship-driven.

It is now extremely rare for long-distance migrants to set off with no knowledge of their final destination. Once examined from within, virtually all contemporary migratory flows turn out to be grounded in processes of chain-migration, such that earlier settlers 
encourage the passage of their kinsfolk to the particular destination at which they have established themselves, who in turn provide similar assistance to further kinsfolk. Such processes rapidly develop their own near-exponential dynamic, most especially when those involved are in a position to draw on extended networks of kinship reciprocity within which to further their collective entrepreneurial exercise. As immigration authorities around the world have discovered, once such chain-migratory escalators are in full flow, such that a substantial number of settlers are strategically located overseas, bringing them to a halt is a well-nigh impossible task (Bhagwati 2003). The dynamics of these powerful engines of socioeconomic change deserve far closer examination than they have hitherto received.

Viewed from above, the internal driving forces which have sustained these developments were entirely unexpected. It is easy to see why. Whilst it was common knowledge that the dynamics of twentieth century globalisation have reinforced the unequal distribution of material assets between Euro-America and the inhabitants of most parts of Asia, Africa and Latin America, it seemed apparent that those standing on the loosing side of the global division of resources for the most part lacked the educational, economic and political resources which would allow them effectively to compete with the global hegemons. However what such gloomy perspectives overlooked is the extent to which the cultural capital available to those who find themselves in such a position can, when suitably mobilised, provide some highly effective strategies by means of which those involved can begin to extract themselves from the positions of hopeless disadvantage to which they might otherwise be condemned. Seen from this perspective, it is now quite clear that by taking advantage of the dramatic falls in the cost of long-distance travel and communications, and given the oftenunacknowledged scale of demand for unskilled labour in most of the world's developed economies, the entrepreneurial potentiality embedded in networks of extended kinship reciprocity have been unleashed with dramatic success. The result has been the construction of innumerable transnational 'escalators' which have emerged to facilitate the transfer of hundreds of millions of people from a host of specific localities in the developing world to equally specific destinations in Euro-America, as well as a number of other prosperous economic hot-spots.

Such developments are best understood as one of the most significant countervailing responses to established patterns of Euro-American global hegemony to have emerged during the course of the past half century. From that perspective these self-generated entrepreneurial initiatives reaching upwards 'from below' have achieved much more than mere populationtransfer. Besides facilitating the growth of ever more prosperous ethnic colonies, the remittances which such settlers transfer through those self-same networks to their kinsfolk back home are now estimated to exceed $\$ 250$ billion per annum, greater than the global flow of development aid. They now form a stable, counter-cyclical source of development aid, transferred directly into the pockets of the poor (Ratha and Maimbo 2005).

No less than their counterparts operating 'from above', the transnational networks which have recently emerged from below are strongly corporate in character: that is the key to their success. But in contrast to the formal bureaucratic structures on which multinational corporations rely, those deployed by the countervailing entrepreneurs operating from below operate on a much more 'informal' basis. By making the most of the potential for corporate activity embedded in their kinship systems, they have found themselves able to redistribute persons, ideas and capital within their global networks with just as much facility, but with much lower overheads than those incurred by more formally organised multinational corporations (Ballard 2005). Given this, it should be apparent why European expectations 
about the prospect of settlers rapidly abandoning their prior cultural commitments have proved to be so wide of the mark. Far from falling into abeyance as a consequence of their transnational extension, the utility of networks of reciprocity has for the most part been actively enhanced in such contexts, so precipitating precisely the opposite outcome. Whilst the results were by no means a carbon-copy replica of what went on back home, for the adaptations made to cope with the demands of new transnational environments were nothing if not far reaching, the institutions around which ethnic colonies crystallised actively facilitated the circulation of information, ideas, financial assets, and of course persons within in a myriad of diasporic networks, so promoting their members economic, educational and spatial mobility (Ballard 2003a, 2003b, Shaw 2000).

As these intrinsically transgressive developments have begun to gather strength, so the very structure of the global order gradually being transformed: by devising strategies by means of which to beat their former hegemons at their own game, the outsiders have begun topple the insiders from their former positions of unchallenged hegemony. But in so doing the upstarts are by no means always choosing to play by the established rules of the game. The strategic initiatives of transnational migrants provide numerous examples of the effectiveness of discarding conventional practices, in favour of the creative deployment of one's alterity the better to circumvent the obstacles lying in one's path, and in so doing to devise yet more efficient and effective solutions to the remaining problems at hand.

\section{Family and Kinship}

In these circumstances it should come as no surprise that preferred kinship conventions of members of Europe's non-European minorities have become the focus of such heated debate. The challenge which their presence offers to the established social order is real, not fictional. Kinship conventions do much more than generate distinctive patterns of inter-personal behaviour; they also have a far-reaching impact on demographic developments, on innumerable aspects of their users' everyday social, personal and strategic practices, and hence on the structure of the wider socio-political order.

How far do migrants' assumptions about family, kinship and marriage differ from those of the indigenous majority? Thanks to the influence of the Church, European (and especially northern European) kinship conventions have traditionally assumed that the institution of marriage stands ipso facto at the core of family life. Marriage, it is routinely assumed, is, or at least should be, a monogamous and life-long heterosexual partnership, established on the basis of a personal choice, and contracted as a necessary precursor to sexual cohabitation. It is also assumed that marriage will precipitate the establishment of an independent nuclear household, within which the offspring of the union will be raised to adulthood. Having reached that condition, it is further expected that these free and autonomous individuals will select partners, marry, and set up similarly structured autonomous conjugal families of their own. To be sure members of these autonomous households still expect to keep in contact with their parents and siblings, but such relationships are sustained by far weaker bonds of reciprocity than those associated with conjugality. Hence, for example, they only expected to be associated with co-residence in contexts of exceptional economic hardship. Such is the overwhelming salience of the conjugal tie that the use of wider relationships of kinship reciprocity as a means of constructing the corporately organised descent and lineage structures is virtually unknown. 
The priority assigned to conjugality in European kinship conventions has been reinforced by a strengthening commitment to individualism with far-reaching consequences: the strength of both inter- and intra-generational kinship bonds was subject to further erosion. Furthermore, conjugal units have not only been rendered steadily more autonomous, but ties of conjugality themselves have now begun to weaken. As obstacles in the way of divorce have been progressively discarded, the frequency of its incidence has increased by leaps and bounds. Likewise marriage has lost its sacramental status. It has ceased to be a regarded as necessary precursor to sexual intercourse, to the production of offspring, or even to the establishment socially acceptable conjugal partnerships; and most recently of all legislative changes have sought formally to confirm that homosexual partnerships should be regarded as having the same level of social and legal acceptability as those constructed on a heterosexual basis. The resulting behavioural changes, accompanied by unprecedented levels of prosperity and spatial mobility, steady increases in life-expectancy, and a rapid decline in fertility rates precipitated by the introduction of reliable means of birth control, have precipitated farreaching socio-demographic changes. Family units are steadily shrinking in size, in some cases almost to the point of disappearance, whilst single-person households are becoming an increasingly commonplace, especially amongst young and affluent members of Europe's indigenous majority.

By contrast the vast majority of non-European settlers continue to operate within the context of ideologies which bind them into all-consuming networks of mutual reciprocity with a far wider range of kinsfolk. Restricting attention to the conventions deployed in that part of the world from which the great majority of settlers have arrived - the swathe of territory which runs from North Africa through the Eastern Mediterranean and the Middle East to South Asia - one common feature stands out. Despite much local and national variation, the conjugal tie is by is far from being the principal foundation of family life. To be sure marriage is a crucial component of the kinship system, but it is nevertheless set within, and to a large extent over-shadowed by a much wider network of inter- and intra-generational ties of mutual reciprocity, largely ordered within the priority given to ties of patrilineal descent (Ballard 1982, 1973).

In such contexts family life is grounded not so much in the conjugal tie between husband and wife, but rather in the more demanding links of mutuality which bind parents, patrilineal offspring and offspring's offspring into all-consuming corporate networks. When ties of reciprocity within the extended family assume such salience, the significance of marriage differs strikingly from that generated by contemporary Western European ideological expectations. Rather than being the very foundation of personal and family life, it is reduced to the status of an appurtenance, albeit one of great significance. Moreover in more corporately oriented contexts marriage gains additional functions which are almost entirely absent in more individualistically oriented systems. Hence besides giving rise to a conjugal partnership between husband and wife, marriage also brings additional domestic partnerships into being, such that in the early days of marriage a newly-arrived bride can often find that her relationship with her mother-in-law, and beyond that with her newly acquired sisters-in-law, is of more pressing concern than that with her husband. Nor is that all. When families are corporately constructed, each new marriage sets up a long-term affinal alliance between the between the two corporations, whilst also providing the wife-receiving family with its most valuable asset of all, a means whereby the descent group can reproduce itself through time, provided that the wife so acquired proves to be fertile. 
Within the context of such conventions each successive marriages mark a crucial step in the development of the corporate family. Carefully selected wives not only add to the group's resources of domestic labour, but are a prospective source of the children whose arrival will ensure that the family's honour and prosperity can be sustained for a further generation. Moreover the arrival of their offspring's offspring marks the point at which parents can begin to feel that having fulfilled their obligation to ensure the continuity of the corporate whole, they can legitimately step sideways into retirement, and receive the respect and support they deserve as a result of having fulfilled their duties. But whilst the strength of the mutual reciprocities so generated may attract some grudging respect, in the eyes of more individualistically minded observers such positive evaluations are swiftly to be overwhelmed by other features of the system. From their perspective there is nothing admirable in cultural traditions in which parents claim the right to superimpose their own priorities over those of their offspring in the choice of their marital partners, where polygamy is accepted as permissible, and where notions of honour and modesty lead to the imposition of such tight constraints personal freedom that homicidal retribution can be precipitated when conventional expectations are seriously contravened. To those whose normative outlook is as individualistic as it is libertarian, behaviours of this kind are nothing less than barbaric.

\section{A Clash of Cultures?}

All this has precipitated much talk of the inevitability of a clash of cultures. External observers regularly suggest that as the locally-raised offspring of migrants reach adulthood they are bound to encounter severe contradictions as they struggle to negotiate the competing demands of their authoritarian and traditionalistically-minded parents and the opportunities for personal freedom to which they have gained access as a result of their participation in the more liberal and progressive cultural order which surrounds them. But although the contradictions between the conceptual premises used to underpin the logic of interpersonal relationships within the two arenas are real enough, are the consequences really so unbridgeable as external commentators routinely suggest must be the case? And perhaps most importantly of all, how sound is their assumption that the prospect of access to unlimited personal freedom, regardless of one's responsibilities to others, will of necessity trump the emotional and material benefits to which membership of a tight-knit network of mutual reciprocity offers to its participants?

Current debates about the legitimacy or otherwise of the everyday lifestyles of members of the new minorities must be approached with caution. Given the extent to which a commitment to individualism and personal freedom is so entrenched in all the contemporary manifestations of Western Europe's indigenous cultural traditions, let alone the strength of the contradictions between the indigenes and settlers outlined earlier, the ideological arena within which debates with respect to such issues currently being played out is anything but level. In such circumstances it is unsurprising that the practices of minority communities, within which a more corporately-oriented set of kinship conventions are utilised as a means of organising their domestic affairs, is routinely perceived not just as bizarre, but as morally and socially unacceptable. In making such negative judgements, external observers invariably focus their critical gaze on the binding obligations, or what are seen as excessively authoritarian demands, which superordinates place on more junior members of the family, thereby substantially compromising their rights to personal freedom. More informed outsiders may well acknowledge that there is much to be said for mutuality and cooperation - after all 
relationships of mutuality may well have provided a valuable source of solidarity in the adverse material conditions in which such settlers' ancestors once lived. But, they ask, for how long can these archaic structures be expected to survive in the midst of contemporary conditions of affluence? From this perspective it seems self-evident that restrictive practices associated with such authoritarian, and as indeed anachronistic, forms of family organisation are everywhere being swept away by irresistible forces of modernity, liberty and personal freedom sweeping the globe.

If the forces of globalisation were indeed destined to have such an effect, efforts by members of the anachronistically-oriented older generation mindlessly to preserve their ancient traditions would soon be overcome by the impact of the rising tide modernity on their locally-born offspring. But how accurate are such prognostications proving to be? To be sure the material aspects of all settlers' lifestyles have changed dramatically since their arrival in Europe; no matter how much they may have striven to sustain more traditional behavioural practices in domestic contexts, their offspring have by now had sufficient contact with the indigenes and their institutions to act in a wholly 'English', 'French', 'German', 'Dutch' or 'Italian' manner as and when they choose. Yet despite their acquisition of the navigational skills which enable them to participate with ease in virtually all the arenas in which the linguistic, social and cultural conventions of the indigenous majority hold sway, it is equally clear that the vast majority of young people of minority descent still stubbornly maintain a strong sense of their own distinctiveness in more personal, domestic and leisure contexts. How is this 'stubbornness' best accounted for? Is it merely a consequence of authoritarian parents imposing traditionalist restrictions on gullible and long-suffering offspring? Or the consequence of charismatic preachers managing successfully to seduce naïve young Muslims into accepting the premises of immoderate Islam? Or is it, to the contrary, that the parallel strategies of non-assimilation, most especially in personal, domestic and leisure spheres, which so many members of the younger generation turn out, on close inspection, to have adopted are better understood as an adaptive, and from that perspective a positive, response to the manifold challenges with which they have found themselves confronted?

That those subjected to systematic patterns of racial and ethnic denigration and exclusion should not only have closed ranks, but deployed all the other characteristics 'weapons of the weak' (Scott 1985, 1990) should come as no surprise. In doing so they have followed a multitude of predecessors by quietly elaborating their sense of alterity, the better to extend the range of strategic resources with which to confront and confound their opponents. In this sense at least, the ways in which members of all the various components of the minority communities, young and old, females and males, are making creative use of the resources of their ancestral heritages in conjunction with all manner of ideas and perspectives quietly borrowed from their hegemons, the better to resist, to circumvent and ultimately to overcome and obliterate the forces of exclusion with which they find themselves confronted, is anything but unprecedented, even in a European context. After all innumerable local minorities have pursued the same tactic, though their deeper local roots have enabled them legitimate their ethnic consolidation as patriotic nationalism. Whilst the new minorities' strategies of resistance may indeed be stubborn, they are anything but a manifestation inherent social pathology: rather they are prerequisite for the achievement of more equitable outcomes. By just the same token those responsible for their marginalisation have just as much interest in sustaining the opposite view. Efforts to demonstrate that all manifestations of ethnic alterity are as unhelpful as they are pathogenic have always been one of the one of the most favoured weapons in the armoury of the strong. 


\section{The Costs and Benefits of Collective Solidarity}

Whatever outsiders might suggest, those who order their domestic lives on a corporate basis are for the most part acutely aware of the most salient benefit of collective solidarity. In the face of the vicissitudes of an uncertain world, mutual cooperation provides a highly effective bastion against the prospect of personal insecurity. However such outcomes only occur if certain conditions are fulfilled. One of the most important is the willingness of those involved to sacrifice their own personal interests in favour of those of the collectivity as and when the a need arises. The unbounded pursuit of personal interests and/or individual freedom is of necessity inimical to collective solidarity. That said, however beneficial to others such behaviour may be, it is by no means necessarily an unmitigated good as far as those required to make such sacrifices are concerned. In principle, at least, their willingness to put their personal interests to one side in the short term should guarantee that they will at some point reap benefits which are at least proportionate to those which they had previously foregone. That is what the principle of reciprocity is all about. But what if the promised returns begin to look far less than the sacrifice made, and the prospect of their fulfilment becomes so distant as to be rendered meaningless?

Such queries are far from hypothetical. No matter how strongly committed to the principles of cooperation and mutuality members of corporately constituted families may be, most also keep a wary eye on the demands which have been placed on them by others. They are rarely so stupid as to assume that in the absence of regular reminders, those who have gained from their sacrifices will of necessity full their reciprocal obligations without having their memories jogged. Contrary to the assumptions of libertarian outsiders whose personal experience has been limited to that of an egalitarian/individualistic conceptual universe, all my experience suggests that those who have grown up within collectively ordered families are rarely so naïve as to assume that the ideology of reciprocity will of itself be sufficient to guarantee their personal interests as against the self-interested machinations of others members of the group. Indeed as anyone with personal experience of the dynamics of interpersonal interactions within such extended families can readily testify, the broad framework of mutuality is simultaneously accompanied, and indeed underpinned, by endless competitive efforts by those involved to scheme and manoeuvre their way to positions of advantage with respect to their personal rivals. Hence even though such groups may close ranks in comprehensive unity in the face of external threats, at a more everyday level the centrifugal forces precipitated by the processes of mutual competition are only marginally trumped by the centripetal forces of mutuality holding the group together.

Once extended families are viewed as processual arenas whose organisational stability is the outcome of a constantly renegotiated condition of dynamic equilibrium, it becomes much easier to gain a better appreciation of the actual operation of what might otherwise appear to be static and authoritarian hierarchical structures. Once this kind of perspective is adopted it is immediately apparent that the female members of such families are relatively rarely reduced to the position of helpless pawns which ill-informed external observers so often assume they must of necessity occupy. On the contrary all my experience suggests that women have an exceptionally keen appreciation of the distribution of costs and benefits within the family, and consequently spend much time and effort executing complex manoeuvres whose principle objective is to advance the interests of both themselves and their offspring. Moreover their husbands are by no means the only alters whose interests they seek 
oppose in so doing. Once one taps into these processes it soon becomes apparent that whilst wives invariably take great care not to topple their husbands from their positions of nominal authority, their partner's ability to determine the course of events within the family is often far more limited than public appearances might suggest. Given the simultaneous presence of mothers-in-law and any resident sisters-in-law within such networks, by far the most explosive contradictions within such extended families tend to be those which periodically erupt between powerful women.

\section{The Dynamics of Constantly Contested Equilibrium}

With such considerations in mind, corporate families relatively rarely take the form of the authoritarian monoliths which haunt the imaginations of external observers. Much changes when they are understood as arenas of mutual interaction where kinsfolk of varying ranks and statuses, bound together by mutually advantageous bonds of mutual reciprocity, constantly engage in a complex set of interpersonal manoeuvres aimed at least at much at advancing the manoeuvrer's own interests (and countering those devised by his or her many rivals) as they are at advancing the interests of the corporation as a whole. From this perspective a vision of happy families is just as misleading as that depicting them as living in constant terror of the untrammelled and arbitrary power of a coldly authoritarian patriarch. Instead such families are best understood as being grounded in a condition of dynamic equilibrium where the centrifugal forces of interpersonal competition are more or less consistently held in check by the commitment to cohesion generated by the manifest benefits of mutual cooperation.

In such circumstances the quotidian distribution power and authority within such families is more the outcome of endless processes of inter-personal manoeuvring than of the ideological commitments around which they are formally constituted. Nevertheless those remain of crucial importance, not least because they provide the yardstick against which participants routinely seek to measure the extent to which others have fulfilled their responsibilities, or failed to do so. From this perspective the overall ideological framework is far less prescriptive than it might seem at first sight. On the one hand it leaves plentiful scope for individual members of the family to establish alliances with others in an effort to advance their own interests, which will very often include those of their immediate dependents; meanwhile it simultaneously provides an equally effective means of seeking to counter and undermine their rivals' parallel manoeuvres, not least by accusing them of failing to live up to those prescriptive ideals. Moreover if the conflicts precipitated by these manoeuvres reach such a degree of intensity as to begin to threaten the integrity of the group as a whole, a further remedy is readily available: the family meeting. Most usually chaired by a respected elder who stands above the fray, the central objective of such an exercise is to facilitate the renegotiation of strained relationships, and on that basis reach a compromise which serves to satisfy the pragmatic interests of all concerned.

Nevertheless family meetings do not always produce the desired outcome. When contradictions have become sufficiently deeply entrenched, and the contending parties so stubbornly committed to their respective positions, such that successive attempts to a broker compromise have all collapsed, it eventually becomes clear that no viable means of resolving the underlying contradiction is available. Such an impasse invariably precipitates a change in the very structure of the collectivity itself, as when marriages are recognised as being in a condition of irretrievable collapse, when brothers who have hitherto organised their affairs 
jointly decide they are no longer able to live together under the same roof, or when no agreement can be reached about a suitable spouse for a son or daughter. When both sides have entirely lost confidence in the others' commitment to mutuality, only one solution is possible: an irretrievable split in the structure of the corporate whole. In such circumstances the elders are likely to change course, and to seek to broker an amicable division of corporate assets and responsibilities. But if the elders fail to calm the hurt feelings which are often harboured by the party which feels itself most aggrieved, violence can all too easily ensue. In such circumstances the bitterness generated when close kin fall out - such that relationships of comprehensive reciprocity are replaced by those of equally comprehensive feud - must be seen to be believed.

To observers raised in societies where networks are shallow and individualism is the order of the day, such outcomes seem quite bewildering. In their world, similar breakdowns are unlikely to precipitate anything more than a short period of anger and resentment before normality is restored. But the larger and more corporate the kinship networks within which such breakdowns occur, the more explosive the consequences of such a collapse in relationships of reciprocity tend to become. It is in these kinds of circumstances that so-called 'honour crimes' tend to occur.

\section{The Consequences of Transnational Extension}

The transnational extension of networks of kinship reciprocity has powerfully reinforced all aspects of these tendencies, both positive and negative. As the settlers themselves are well aware, it is because of their success in sustaining such links of mutual reciprocity amongst themselves, together with their equally substantial success in socialising their overseas-born born offspring into these self-same modes of behaviour, that they have been able to achieve such a dramatic degree of socio-economic mobility, no less in spatial than in vertical terms. However these successes have not been without their downsides. As ever, such exercises demand that all concerned make substantial sacrifices of their immediate interests in the expectation this will provide even more substantial future benefits. But by just the same token there is as much, if not more, danger that those less fortunately placed will find the bulk of the benefits falling into the hands of those better placed than themselves, whilst the established means whereby those so marginalised have hitherto been able to flag their distress have been attenuated by the transnational extension of formerly parochial networks.

If so, it is hardly surprising that the diminished effectiveness of internal modes of reconciliation should have been accompanied by an increase in the scale and severity of contradictions within extended families, and hence in the frequency of violent interpersonal confrontations amongst kinsfolk. But if so, how should such developments be read? Viewed through the prism of contemporary European liberal/egalitarian conceptual expectations, the answer seems obvious. The kinship structures which such migrants have brought with them were inherently patriarchal and authoritarian in character, and led to the imposition of wholly unjustifiable limits on the personal freedom of those who consequently found themselves at the bottom of the resultant hierarchy. But as a result of the transfer of such families to a more open and progressive environment, the underlying contradictions have grown unsustainably wide. Hence the oppressed victims of these processes have at long last begun to challenge their subordination, and husbands, fathers and brothers have sought to reassert their traditional 
authority by violent means, so precipitating the gruesome outcomes so regularly reported in the media.

However satisfied with such explanations external observers may be, not least because they are both congruent with and serve yet further to reinforce their prior assumptions, a view from within invariably throws up far more complex representations of what is going on, albeit of a kind which external observers regularly regard as close to incomprehensible. Why should this be so? In my experience the problem starts with such observers' difficulty in gaining an appreciation of just what the concept of reciprocity might mean in these circumstances, most especially in the sense of the long-lasting patterns of duty and obligation to which relationships ordered in this way are expected to give rise. Likewise the concept of personal sacrifice which arises in such contexts, and especially the suggestion that this might be a noble and honourable way of behaving is one which most contemporary European observers find as bizarre as it is alien. From their perspective, behaviour which contravenes deeply held assumptions about the way in which personal dignity arises from the freely expressed exercise of personal choice - as the notion of sacrifice necessarily demands - is wholly unacceptable. Hence the prospect that such behaviour should be evaluated so positively is by definition incomprehensible.

This in turn serves to highlight the immensity of the conceptual gulf between the cognitive universe in which contemporary Euro-American thinking and action is routinely set, and the social and conceptual universes within which most of the worlds' non-European populations order their daily activities and mutual interactions. Amongst the latter, corporately-organised kin groups, rather than free-standing, autonomous personal-contractmaking individuals are the building blocks of the social universe. Within such a universe personal freedom in the contemporary Euro-American sense stands at a discount, not a premium. Indeed those who occupy such a position of 'freedom' stand, by definition, in lonely isolation, excluded from the world of mutual obligations around which the social order is constructed. From the perspective of those operating within such collectively ordered systems it is the fulfilment of obligations, as opposed to the exercise of rights, which is assumed to provide the foundation of the social order. From that perspective the notion that individuals might have free-standing personal rights vis-à-vis others which can legitimately be exercised on an a priori basis is regarded as entirely alien. Instead, human rights in the Euro-American sense are perceived as a dependent variable, in the sense that they arise as a consequence of the fulfilment of one's obligations to others, and not least to the members of the family into which one has had the good fortune to be born. Hence just as parents sacrificed their own interests, and thereby fulfilled their own necessary obligations, by raising their children to adulthood, so those children are regarded as having a consequent obligation to respect and obey their parents, and to repay them for all their efforts by offering them unstinting support when in due course they become elderly and infirm. In such a world rights of all kinds are not given, but earned on the basis of the fulfilment of the many obligations due to the group of which one is a member, in the confident expectation that one's sacrifices will in due course be repaid (Ballard 1982, 1973).

\section{Transnational Marriages}

Marriage plays a key role in these long-term processes. Marriage facilitates the on-going continuity of corporate families, since it is a necessary prerequisite for the production of the 
heirs who will carry the group forward into the next generation. It also plays an equally significant role in building strategically advantageous inter-familial ties of affinal reciprocity which supplement, or provide a counterpoint to, the less malleable patterns of alliance and differentiation precipitated by patrilineal descent. Whilst the strategic use of marital manoeuvres to achieve such objectives may now have fallen into abeyance in Euro-American contexts, they were once of pressing concern to the aristocracy and landed gentry of medieval and early modern Europe, and continue to be the very stuff of village politics in those parts of world where extended kinships networks, and through them the hereditary distribution of rights in land, provide the foundations of the local socio-economic order. It is of course from societies of the latter kind from which the vast majority of the settlers with whom we are concerned here have been drawn.

Had those who implemented such practices stayed in their villages, it might have been possible to dismiss such match-making manoeuvres, as the competitive quests for strategic advantage which underpin them as arcane matters of little concern to anyone but kinshipbesotted anthropologists. But given the key role played by kinship reciprocities in the construction and maintenance of escalators of chain migration, there is no way in which such judgements can be sustained. Instead, concern with such matters has become a substantial focus of social policy throughout Western Europe. It is not difficult to see why. Migrants have been no less entrepreneurial in circumventing immigration controls than they have in any other sphere, so causing many migration managers to conclude that they have been saddled with a wholly impossible task. In the face of directions from on high to bring the inflow of non-European immigration under control, they found their targets deploying what they perceive as being every trick imaginable in their efforts to evade the controls they are required to enforce. Moreover their attempts to plug the resultant gaps are regularly rendered nugatory by 'unhelpful' restrictions such as those arising from the European Convention on Human Rights, or from the provisions of asylum law. In consequence, immigration law has everywhere been transformed into an arcane game of cat and mouse.

The result is a complex stand-off, in which marriage has become a central bone of contention. It is now nearly forty years since the UK authorities took their first steps towards closing off unlimited primary migration, or in other words the entry of young unmarried adults who had not been granted work permits. However, one of the central consequences of their efforts has been to divert the inflow of what was once expected to be a self-limiting source of future arrivals, the immediate kinsfolk of established settlers. But 'secondary migration', as this inflow was initially described, has not followed the expected pattern, remaining as vigorous as it was when immigration controls were introduced. As marriage emerged as the weakest link in the authorities' exclusionary provisions, so it has become an ever-more contentious battleground.

In the early days of settlement the vast majority of 'secondary' applicants were the wives and children of men who had already established themselves in the UK. In an effort to curb their inflow the authorities queried the legitimacy of the applicant's marriage, and/or whether all the children accompanying her were indeed the offspring of the sponsor. That strategy temporarily served to curb the inflow, until the introduction of DNA tests provided an incontestable means of identifying parentage. When the great majority of contested claims proved to be valid, the inflow resumed with a vengeance, precipitating ever more intense pressures to bar the door once again. Further initiatives were introduced, but none proved more effective than the 'primary purpose' rule, which was by now directed at excluding not 
so much the wives of men who had entered the UK as adults, but rather the spouses of those of their UK-based offspring who had reached marriageable age.

In this respect the dilemma facing the immigration authorities was even more challenging. If members of the rising generation chose (or rather responded positively to their parents suggestions that they should choose) a spouse from back home, how could the couple be prevented from taking up residence in the UK? The obvious answer was to challenge the legitimacy of the marriage itself. This led to the construction of the notorious 'primary purpose' rule (Sachdeva 1993) which targeted couples whose relationship was not preceded by a period of courtship, in other words whose marriage had been arranged. By demanding that the overseas-resident partner seeking entry into the UK should demonstrate that achieving that goal was not the primary purpose of their marriage, all such applicants were required to prove a negative before they could be granted a right of entry into the UK. Whilst this rule served its purpose for a while, such was the wave of criticism that its continued application became indefensible, and it was abandoned by the 1997 Labour government). Nevertheless the underlying contradictions remained as vigorous as ever, and no effort was spared in the search for a viable alternative.

In doing so an approach initially developed in Norway has begun to attract increasing attention in many other parts of the EU, including the UK. It is easy to see why. Just like the 'primary purpose' rule it seeks to de-legitimise a whole category of marriages. The Norwegian approach was grounded in the vocabulary of human rights, and the proposition that 'forced' marriages were thereby inherently illegitimate. It was further argued that those forced to contract such marriages were typically cousins, and/or spouses aged under the age of twenty-five (Bredal 2005). Since marriages where those conditions were fulfilled were most unlikely to have been based on personal choice, and therefore compromised the human rights of one or both partners, it was entirely legitimate to remove the exemption of spouses who had married on that basis from immigration controls. By adopting such an approach migration-managers clearly hope they have at long last found secure ground on which to base their arguments. They may well be right. So far at least, legislative initiatives grounded in appeals to human rights, to individual freedom and to the necessity of curbing the evils of patriarchy, have attracted widespread support. No-one denies that such measures also provide a strategically convenient means of reinforcing the effectiveness of Europe's carefully constructed barriers of immigration control; however the justification of such measures on human rights grounds provides an excellent means of assuaging both legal criticism and liberal consciences.

That said, it is no part of my argument that marriages of the kind which such seek to target are necessarily problem-free, far from it. But if such matches do indeed display an alarming tendency to be beset by personal contradictions, I would argue that such problems are best addressed on a basis which is a good deal more sensitive to the perspectives of the actual participants. Why, then, might insiders choose to contract such transnational marriages? That question can be answered at a number of different levels. The first and most obvious answer is that if one's personal social arena is transnationally extended, and if one also expect to find a spouse 'of one's own kind' within such an arena, then the process of spouse-choosing is also likely to conducted on a transnational basis. Hence, for example, a young Sikh who has grown up in Birmingham is as likely to meet a potential spouse whilst visiting Leeds to attend a marriage as when he (or she) attends a similar event in Vancouver or Phagwara. Likewise if such spouse-hunters turn to the Internet to expand their range of choices, they may well use a religious, and indeed caste-specific, website of global scope. In 
this, as in many other spheres, transnational networks progressively render national boundaries irrelevant, widening the opportunities for exercising strategic choice and developing entrepreneurial opportunities, and simultaneously enabling one to exploit and reinforce the resources of the network to which one is affiliated.

There are a several more specific reasons why members of the older generation find the prospect of locating spouses for their offspring from back home particularly attractive. Amongst the most straightforward is the wish to recruit a daughter-in-law who is comprehensively steeped in the values of one's ancestral tradition, such that she will be able to pass those traditions on to one's grandchildren on a far more effective basis than an overseas-born and raised daughter-in-law could ever hope to achieve. At the other end of the scale such a match is also widely regarded as a convenient backstop when all else fails - as for example when some aspect of a son's or a daughter's behaviour, experience, appearance or health is such that the prospect of finding an appropriate spouse in the local marriage market has been virtually eliminated. However the pressure to migrate - as migration managers have come to describe it - arising from this source is relatively limited. The situations which have caused them a great deal more concern are those in which transnational spouse recruitment appeared (at least from their perspective) to have been deployed in deliberate efforts to exploit loopholes in their carefully constructed system of immigration control. These fall into two main classes. Firstly those marriages in which parents of overseasbased spouses paid large dowries in return for the privilege of being able to see their son or a daughter to reach the preferred destination; secondly, and much more frequently, those in which the spouse in question was a close relative, most usually a cousin, of his or her UKbased spouse, and whose primary purpose appeared to be to enable an additional member of the biraderi (descent group) was able to join the otherwise halted escalator. It is with such concerns in mind that cousin-marriage has come figure so largely in current efforts to block what ha come to be regarded as the family-reunion loophole in the bastion of Fortress Europe.

\section{Marriage Rules and their Consequences}

As I argued in a paper published nearly two decades ago (Ballard 1990), the conventions deployed within any given community with respect to just what categories of kinsfolk one may and may not marry can have a far reaching impact on the precise way in which transnational escalators of chain migration develop over time. In an analysis which appears to have helped to have spark off the subsequent debate in Norway, I explored the comparative impact of the conventions deployed by Muslim emigrants from Pakistani Punjab, which are largely derived from the incest taboos set out in Leviticus, with those deployed Sikh and Hindu neighbours from Indian Punjab who follow complex rules of gotra exogamy.

The central consequence of these conventions is that whilst Hindus and Sikhs are effectively barred from contracting marriages into families with whom they have any prior links of kinship, Punjabi Muslims are subjected to no such restrictions, such that marriage between cousins is regarded as entirely permissible. These differences have far-reaching consequences when parents set about choosing partners for their offspring. Thanks to the rules of exogamy, every Sikh and Hindu marriage has to be negotiated afresh with 'strangers', or more precisely, with non-kin. Revealingly, the term rista means both marriage and relationship, so highlighting the extent to which every marriage also generates a vigorous link of affinal reciprocity between the givers and the recipients of the bride. But although riste 
have exactly the same relationship-building consequences in Muslim contexts as they do for Sikhs and Hindus, the absence of exogamous restrictions have strategic implications. Hence whilst Punjabi Muslims are aware well aware of the benefits of using carefully negotiated marriages as a means of building alliances with non-kin, their much more usual practice is to deploy their riste as a means of reinforcing existing ties within the agnatic biraderi. Similar choices are also exercised across the length and breadth of the Islamic world, but nowhere does the option appear to be more actively pursued than in the Punjab, where more than half of all marriages are arranged between first cousins.

Why, though, do Punjabi Muslims exercise this choice so frequently? One of the most important factors behind this preference in the exceptional intensity of the bonds of emotional reciprocity between siblings, such that siblings expect to be able to exercise a right of first refusal when it come to arranging the riste of each others' children. In these circumstances, to refuse such offer of rista without good cause is regarded as a repudiation of one of the key obligations of sibling solidarity, not a step to take lightly. Nevertheless there is a further counterpoint to this. If the sibling group in question is of any size, there will be a large number of potential permutations as to how the marriages of the cousins in the next generation might be arranged. Moreover those choices are multiplied yet further by the fact that the offspring of a wife's siblings, no less than those of her husband's, are all in play when it comes to the negotiation of riste. In these circumstances a preference for cousin-marriage is normally far from being narrowly prescriptive. Nevertheless this practice does have two obvious outcomes. let alone the fact that wives, no less than husbands are actively engaged, and in consequence frequently in competition with one another, in an effort to ensure that the riste constructed for each of their offspring fall as far as possible to their own strategic advantage. When a high proportion of all riste are arranged between cousins, descent groups (biraderi) become much more tight-knit and in-turned than in communities in which marriages are expected to conform to rules of exogamy. Secondly, and just as significantly, no matter how tight-knit such biraderi might seem when viewed from an external perspective, their internal processes of internecine micro-politics whose roots are more often than not generated by squabbles both between siblings and between husbands and wives over exactly where such riste-alliances should be placed, are also exceptionally vigorous, even if they are largely inaccessible to external observers.

In no way did the establishment of transnational escalators interfere with these practices: all they did was to extend the spatial dimensions of the arena within which these manoeuvres took place. Hence as soon as their overseas-raised offspring began to reach marriageable age Muslim parents, no less than their Sikh and Hindu counterparts, began explore where their riste could be most suitably be placed, and in like manner began to receive offers of riste for their offspring from back home. Whilst the settlers initial response was to continue deal with these offers on the basis of their established priorities, and hence to make their choices as if they had never left home, it was not long before significant differences began to emerge as between the out-marrying Sikhs and Hindus and the inmarrying Muslims, largely as a result of pressure from their offspring. Even though the principles around which their domestic lifestyles were organised differed little from those with which the spouses their parents were likely to select for them expected to operate, other dimensions of their everyday lifestyles had been much more heavily influenced by the wider British context within which they had been brought up. Moreover it soon became apparent that many couples found the resultant contradictions difficult to negotiate, so much so that the very stability of their marriage could be compromised. However the reaction of Sikh and 
Hindu parents to these developments differed significantly from those of their Muslim counterparts.

Faced by ever more insistent protests from their offspring that matches ordered according to their own established priorities were in considerable danger of collapsing as a result of the impact of these contradictions, Sikh and Hindu parents began to revise their priorities. Whilst insisting that all such riste should still be arranged in conformity to the rules of caste endogamy and gotra exogamy, they nevertheless agreed that those conditions could still be satisfied by looking for matches with other families who had already made a similar move into the diaspora, no matter how well-connected the source of such an might be. After all they were under no obligation to make a positive response to such offers. By contrast parents belonging to communities in which cousin-marriage was the norm found themselves in a very different position. When similar offers of riste on behalf of their offspring arrived, the proponents were not strangers, but their own siblings. Such offers could not be lightly refused. Doing so would not only be read as a denial of their obligations of siblingship, but a deliberate effort to repudiate their nephews' and nieces' efforts to gain access to all the many benefits which they had themselves, by great good fortune, acquired.

Such pressures became even more intense as migration managers progressively tightened entry criteria, such that marriage became virtually the only legitimate basis on which kinsfolk of established settlers could gain a permanent right of abode in an affluent and highly-developed European environment. Hence whilst the young people whose domestic and personal futures were being determined by their parents' choices were for the most just as concerned about their likely prospects as were their Hindu and Sikh counterparts, any protests they might make met with much more adamant opposition from their parents. The dilemma they faced was acute. However reasonable they might consider the appeals of their offspring , they had to weigh them against the prospect of compromising the fundamental principles of sibling solidarity. Could they bring themselves to repudiate the interests of close kinsfolk by denying them assistance in attaining, like themselves, the benefits associated with residence in a far more affluent and opportunity-ridden society? Many could not bring themselves to treat their kinsfolk in such a heartless fashion. The impact of their decisions is immediately apparent in the immigration statistics. Close to $50 \%$ of young UK-based Pakistanis still contract marriages with spouses from back home. By contrast the percentage of Hindus and Sikhs contracting such marriages has long been in single figures.

That said, what are we to make of the likely emotional impact, let alone the personal consequences, for young British-born spouses who find themselves despatched to a rural corner of the subcontinent to fetch their future life-partner? Or, for that matter, for his or her partner-to-be, for whom marriage will likewise entail a transfer to a physical and material environment wholly unlike anything she or he has hitherto experienced? Such prospects routinely precipitate reactions of intense alarm amongst external observers. To those whose normative expectations are individualistically-oriented, the prospect of being required to enter such a transnational conjugal partnership in the absence any significant degree of personal choice, let alone a period of prior courtship, appears to be quite unconscionable. Moreover every news item reporting the collapse of such marriages reinforces their belief in the soundness of such a judgement. If, however, we switch to an insider's perspective, a rather different picture emerges. This is in no way to discount the potentially pathogenic consequences of the underlying contradictions already identified, but rather to set them within wider continuities. Over and above those associated with the transnational arena to which the wider network has itself has given rise, brides who marry their cousins do not enter their in- 
laws' households as total strangers, as is the case in those communities where marriages are construed by rules of exogamy. Not only will such spouses have been well aware of each other's existence long before the marriage took place, but the bride will enter a household in which either her mother- or her father-in-law will be a sibling of one of her parents, and will consequently have an active interest in the rista's successful implementation.

Likewise the absence of courtship prior to marriage must also be placed in its appropriate context. Although the UK-resident spouse will be well aware of, and will in all probability have dabbled in, alternative modes of pre-marital engagement with members of the opposite sex, both will also have been brought up in domestic arenas in which normative conventions suggest that such behaviour is not only intrinsically shameful, but also in no way a necessary precursor to a successful marriage. At the same time Punjabi parents are far from naïve on this score. They are well aware, not least on the basis of personal experience, that once the rush of hormonal activity precipitated by puberty is in full flow, their offspring can only be expected to develop an acute interest in the prospect of sexual activity, no matter how carefully they have been brought up. In consequence they take a very pragmatic view of temptations with which their offspring are likely to find themselves confronted unless those natural urges are suitably assuaged. At the same time their concerns are powerfully conditioned by considerations of izzat (honour) and sharam (modesty), both of which have a far-reaching impact on the standing of the family within the biraderi. Such concerns are also strongly gendered. As in many other cultural traditions, few parents are greatly concerned about the prospect of their sons sowing wild oats, always provided they take care to distribute them well beyond the bounds of their own immediate community. By contrast the prospect of one of their daughters emulating such behaviour, even to the mildest possible degree, can have disastrous consequences. Besides severely compromising her own personal reputation, her actions will lead to humiliating shame being poured on the izzat of every other member of the corporate family.

Many members of the older generation take the view that marriage provides a sovereign remedy to - and indeed a prophylactic against - problems of this kind. If sexual activity is a necessary and natural function, it makes much better sense to facilitate its exercise in a legitimate rather than an illegitimate context, and to provide one's offspring with opportunity to do so as soon as is reasonably possible. Nor has the passage to Britain undermined that view. Having observed that their indigenous neighbours appear to be wholly unable to prevent their children to engaging in what appears to be unbridled sexual activity, many Punjabi parents find themselves becoming yet further committed to what is for them a well established remedy: early marriage. On the grounds that the mutual affection which is the necessary foundation of a sound conjugal relationship is much better rooted in marriage, rather than in the purely animal passions let loose in an unregulated period of nominally premarital courtship, they take the view that exposing children to the prospect of legitimate sexual activity just as their biological urges are reaching their peak provides by far the most effective foundation for a life-long partnership. Of course most will also readily acknowledge that such strategies by no means always produce the desired result, but in doing so also note that if divorce rates are used as a yardstick of success, their own preferred solutions fare extremely well in comparison with those championed by their critics.

However the moment one adds the dimension of gender further complexities arise. Whilst arguments of the kind rehearsed above become urgent once daughters reach their late teens, Punjabi parents give every appearance of being far more relaxed about the behaviour of their sons. However most are merely biding their time. Once sons reach their mid-20s, and all 
the more so if there appears to any danger of their becoming inextricably involved with a girlfriend who would in their view would be incapable of adequately fulfilling the role of daughter-in-law, parents rapidly step in to take remedial action Having begun by reminding their errant heir of the debt of loyalty he owes to his progenitors, they will swiftly set about bringing a series of potentially attractive riste to his attention. If he should reject all such suggestions that will by no means be the end of the matter. Support will be called in from ever mores distant depths of the biraderi, and before long the errant son will find himself under ever greater pressure to return to the Punjab with the entire family in search of a suitable bride. Nor are such strategies reserved solely for sons. Daughters who are perceived to have 'gone off the rails' regularly find themselves subjected to exactly the same treatment. In such circumstances the pressure to conform to established expectations invariably becomes intense. Some resist for all they are worth. Many, however, eventually succumb, and accept one or other of the proposals put before them.

Should the outcome of such exercises be described as a 'forced marriages'? That is certainly the case as far as most newspaper editors and sub-editors are concerned. Moreover there can be little doubt that there is usually considerable substance to the lurid accounts of distress and personal exploitation beneath the dramatic headlines with which even serious publications seek to titillate their readers when they print such stories. But could it be that such accounts serve to conceal as much as they reveal? How far do the journalists who prepare such stories explore the wider context within which the events in question occurred? Or are their accounts unreservedly partial? Is it indeed the case that all such marriages contracted on this basis necessarily end in disaster? Or could it be that in many, perhaps even in most, such cases, combination of the emotions generated by sexual engagement, the birth of offspring, and above all the unstinted support of family and kinsfolk can lead to outcomes very different from those which the headlines so regularly suggest? And above all are draconian - although nominally libertarian - legislative initiatives whose subtext is firmly grounded in considerations of immigration control the most appropriate way to deliver lessons in marriage guidance, let alone to disentangle and renegotiate the tangled contradictions which may have arisen in such circumstances?

\section{Conclusion}

To those who have been socialised into assuming that individual rights, and consequently the capacity to exercise largely unfettered personal choice provide the necessary foundation of any kind of reasonable and equitable social order, many of the values, practices and manoeuvres highlighted in this chapter will doubtless appear to be as unconscionable as they are barbaric. But to those socialised into a conceptual order which accords greater priority to the fulfilment of obligations to others than it does to the exercise of personal choice, it appears entirely reasonable that every effort should be made to facilitate both corporate coherence and the on-going process of family development. From that perspective it makes just as much sense that every possible effort should be made to ensure that those who might otherwise go astray are firmly reincorporated into the networks of familial reciprocity, within which their prospects for personal security would be far greater than if they were to drop out into a world of chaotic individualism. Moreover such claims are far from idle; by and large such strategies work. In an unstable world, corporate families deploying strategies of this kind continue to enjoy a remarkable degree of coherence and stability, as the global success of the transnational networks of which they are the building blocks amply demonstrates. 
That said, no set of kinship conventions yet constructed is a model of perfection: all have their downsides. If contemporary Euro-American conventions offer almost unlimited freedom of choice, they do at the cost of rapidly attenuating levels of personal security; and while more corporately oriented systems offer high levels of personal security to those willing to submit themselves to the obligations required to the maintenance of networks of reciprocity, they do so at an equally necessary cost: the attenuation of personal freedoms of choice.

With such contradictions in mind, it is worth remembering that the expression of acute concern for the helpless victims of barbarian gynophobic practices as a strategic means of establishing the legitimacy European hegemony is in no way unprecedented. Could it be that current initiatives to suppress Forced Marriage, Cousin-Marriage and Honour Killing are merely a replication of those which led the East India Company to celebrate its efforts to suppress Suttee and Thugee? A recent study highlights the way in which missionary arguments supporting such initiatives

hinged on the assertion that the victims were British subjects and due all the respect and protection accorded to British subjects at home: "Yes, it is in British India, where these agonizing shrieks are heard, where the blood of these Widows flows into a torrent, and where these cries of miserable Orphans are heard” (Pennington 2005: 98)

It seems that we have been here before.

\section{References}

Ali, Kalra, and Sayyid (eds.), A Postcolonial people: South Asians in Britain. London: Hurst.

Ballard, Roger (1973), 'Family Organisation amongst the Sikhs in Britain', New Community 2: $12-23$.

Ballard, Roger (1982), 'South Asian Families: Structure and Process', in R. Rapaport and M. Fogarty (eds.), Families in Britain, 179-204. London: Routledge.

Ballard, Roger (1990), 'Migration and Kinship: the differential effect of marriage rules on the process of Punjabi migration to Britain', in C. Clarke, C. Peach, and S. Vertovec, S. (eds.), South Asians Overseas: Contexts and Communities, 219-249. Cambridge: Cambridge University Press.

Ballard, Roger (2003a), 'The South Asian Presence in Britain and its Transnational Connections' in H Singh, and S. Vertovec (eds.), Culture and Economy in the Indian Diaspora, 197-222. London: Routledge.

Ballard, Roger (2003b), 'A case of capital-rich under-development: The paradoxical consequences of successful transnational entrepreneurship from Mirpur', Contributions to Indian Sociology (n.s.) 37 (1\&2): 49-81. 
Ballard, Roger (2005), 'Coalitions of Reciprocity and the Maintenance of Financial Integrity within Informal Value Transmission Systems: the operational dynamics of contemporary Hawala networks', Journal of Banking Regulation 6 (4): 319-352.

Ballard, Roger (2006), 'Ethnic Diversity and the Delivery of Justice: The Challenge of Plurality’, in Prakash Shah, (ed.), Migrations, Diasporas and Legal Systems in Europe, 29-56. London: Routledge Cavendish.

Ballard, Roger (2007), 'Living with difference: a forgotten art in urgent need of revival?', in J. Hinnells, Religious Reconstruction in the South Asian Diasporas: From one generation to another, 265-301. London: Palgrave Macmillan.

Ballard, Roger (ed.) (1994), Desh Pardesh: The South Asian Presence in Britain. London: Hurst .

Bhagwati, Jagdish (2003), ‘Borders Beyond Control), Foreign Affairs 98 (1): 98-106.

Bredal, Anja (2005), ‘Tackling forced marriages in the Nordic Countries: between women's rights and Immigration control' in N. Welchman, and S. Hossain, "Honour" Crimes, Paradigms and Violence Against Women, 332-369. London: Zed.

Pennington, Brian (2005), Was Hinduism Invented? Britons, Indians and the Colonial Construction of Religion. New York: Oxford University Press.

Ratha, D., and Maimbo, S.M. (2005), Remittances: Development Impact and Future Prospects. Washington DC: The World Bank.

Sachdeva, Sanjiv (1993), The Primary Purpose Rule in British Immigration Law. Stoke-onTrent: Trentham.

Scott, James (1985), Weapons of the Weak: Everyday forms of Peasant Resistance New Haven: Yale University Press.

Scott, James (1990), Domination and the Arts of Resistance: Hidden Transcripts. New Haven: Yale University Press.

Shaw, Alison (2000), Kinship and Community: Pakistani Families in Britain. London: Routledge. 